\title{
An integrated workflow for fracture characterization in chalk reservoirs, applied to the Kraka Field
}

Maria Aabø, Tala; Sören Dramsch, Jesper; Würtzen, Camilla Louise; Seyum, Solomon; Welch, Michael

Published in:

Marine and Petroleum Geology

Link to article, DOI:

10.1016/j.marpetgeo.2019.104065

Publication date:

2020

Document Version

Peer reviewed version

Link back to DTU Orbit

Citation (APA):

Maria Aabø, T., Sören Dramsch, J., Würtzen, C. L., Seyum, S., \& Welch, M. (2020). An integrated workflow for fracture characterization in chalk reservoirs, applied to the Kraka Field. Marine and Petroleum Geology, 112, [104065]. https://doi.org/10.1016/j.marpetgeo.2019.104065

\section{General rights}

Copyright and moral rights for the publications made accessible in the public portal are retained by the authors and/or other copyright owners and it is a condition of accessing publications that users recognise and abide by the legal requirements associated with these rights.

- Users may download and print one copy of any publication from the public portal for the purpose of private study or research.

- You may not further distribute the material or use it for any profit-making activity or commercial gain

- You may freely distribute the URL identifying the publication in the public portal 


\title{
An Integrated Workflow for Fracture Characterization in Chalk Reservoirs, Applied to the Kraka Field
}

\author{
Tala Maria Aabø $\varnothing^{\mathrm{a}, *}$, Jesper Sören Dramsch ${ }^{\mathrm{a}}$, Camilla Louise Würtzen ${ }^{\mathrm{a}}$, \\ Solomon Seyum ${ }^{\mathrm{a}}$, Michael Welch ${ }^{\mathrm{a}}$ \\ ${ }^{a}$ The Danish Hydrocarbon Research and Technology Centre (DHRTC), \\ Technical University of Denmark, \\ Elektrovej 375, \\ 2800 Kgs. Lyngby, Denmark
}

\begin{abstract}
Oil and gas production of tight chalk reservoirs frequently rely on the presence of natural fractures, which increases the effective permeability of the reservoirs. Fracture characterization is therefore imperative in optimizing production schemes and obtaining economically viable recovery factors. Subsurface fracture characterization is often deemed challenging as the available data is typically of varying age and quality, and represents different scales. We have developed an integrated workflow for fracture characterization in chalk to address these challenges. The workflow is based on data from borehole images, cores and seismic. These data are typically available for most chalk (and hydrocarbon) fields. The interpreted borehole image dataset contains over 17000 manual dip picks, ensuring a statistically viable base. A total of $150 \mathrm{~m}$ of core is available from 3 wells. The applied 3D seismic cube covers a $8 \times 5 \mathrm{~km}$ hydrocarbon chalk field in the Danish North Sea.
\end{abstract}

In this workflow, the scale-gap between the data sets is bridged by the introduction of two ant-tracked attribute volumes, which display structural trends below the resolution of amplitude seismic. Further insight into the intricacy of subsurface fracture systems is obtained from fracture density logs, which provide an opportunity to study spatial distribution of fractures as well as a qualitative measure of fracture clustering. Cumulative density distribution plots and calculation of the variation coefficient of fracture spacing provide a more quantitative analysis of the fracture distribution.

The workflow, presented here in a step-by-step manner, is a general approach applied to data from the Kraka Field of the Danish North Sea. In the Kraka Field, the usage of this integrated approach shows that the fracture pattern in this region is more complex than previously suggested; probably controlled by

\footnotetext{
${ }^{*}$ Corresponding author

Email address: talama@dtu.dk (Tala Maria Aabø)
}

Preprint submitted to Marine \& 8 Petroleum Geology

October 3, 2019 
the regional maximum horizontal stress and salt movements.

Keywords: reservoir characterization, fractures, structural correlation, borehole images, core analysis, seismic attribute volumes, ant-tracking, chalk

\section{Introduction}

Chalks typically represent high porosity - low permeability reservoirs, in which natural fractures are essential for hydrocarbon production (Koestler and Reksten, 1992).Knowledge of these fracture systems is often used strategically in well planning and in IOR and EOR efforts. Descriptions and models of natural fracture systems allow for simulation of flow and flow patterns in reservoirs, which in turn helps in understanding the quality and amount of hydrocarbon reserves. Natural fractures define the communication in reservoirs, which is the determining factor for well-placing decisions and setup of production schemes for IOR technologies (e.g. water flooding) and EOR technologies (e.g. smart water / chemical flooding).

Accurate predictions of natural fracture systems require an understanding of the controls on fracture orientations and distributions in an area (Fern $\varnothing$, 2012). We have developed a workflow to correlate structural features at different scales, based on borehole image-, core- and seismic data. The applied seismic data includes an amplitude volume and two ant-tracked volumes. High resolution lineations mapped on the two ant-tracked cubes (generated through a variance cube and through RGB-image processing of the 3D seismic volume, respectively) enables detection of smaller-scale lineations below the resolution of conventional seismic, thus bridging the scaling-gap between well and seismic data. Spatial distributions and fracture clustering is considered using fracture density data.

The suggested workflow has been applied to the Kraka Field. The Kraka Field, an asymmetric anticlinal structure located in the Danish Central Graben (Figure 1), was chosen as a test-case as it is a relatively simple structure with a manageable amount of data. The applied data was provided by Maersk for the purposes of this research project. Kraka is produced mainly from the Danian Ekofisk Formation but also from the Maastrichtian Tor Formation, both of which are naturally fractured chalk reservoirs (Jorgensen and Andersen, 1991).

Combining the three aforementioned data types in an integrated workflow allows for the extrapolation of fractures away from the borehole, increasing our holistic understanding of the natural fracture distributions, in this case of the Kraka Field. Using this integrated approach we are able to evaluate orientations of lineations from well- to seismic scale, allowing for structural modelling based on a geological conceptual model. 
Our results will serve as inputs into a discrete fracture network model (DFN) founded on geomechanical principles for fracture propagation, which will improve future well planning and EOR activities in the area.

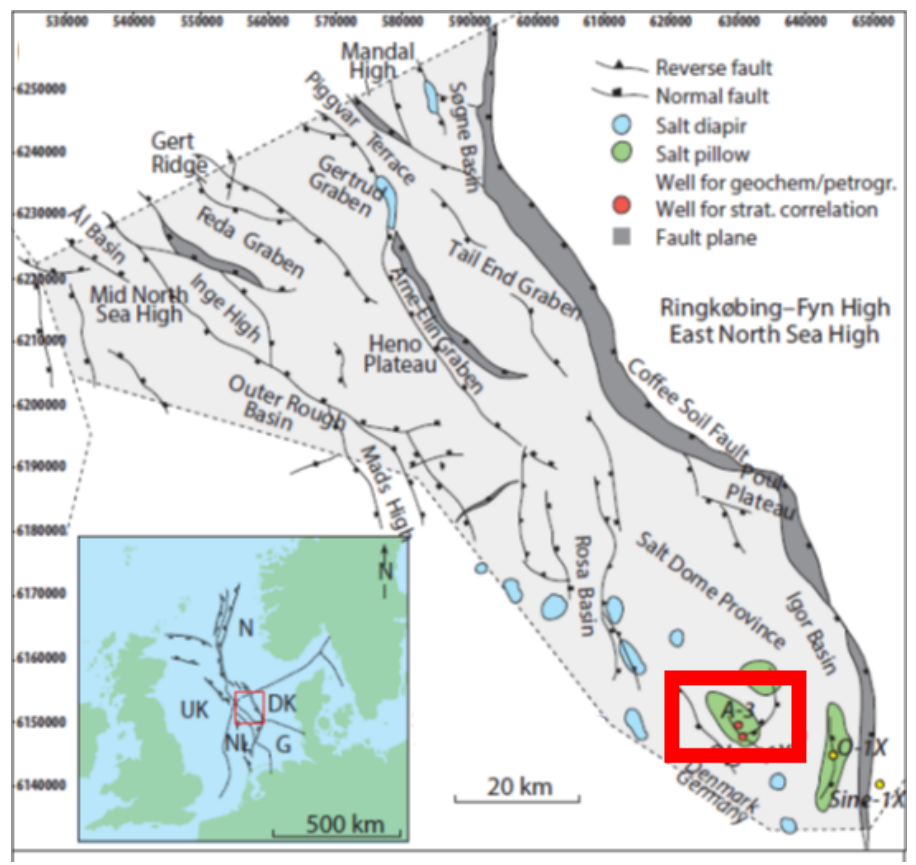

Figure 1: Location of the Kraka Field, indicated by the red square, on a structural elements map of the Danish Central Graben (modified and edited from Møller and Rasmussen (2003)).

\section{Geological Setting}

Prior to applying the workflow, the geological setting of the Kraka Field was considered.

The Kraka anticline was induced through halokinesis. Initiation started during the Triassic and continued to move during the remaining Mesozoic (RankFriend and Elders, 2004). The structure stretches more than $8 \mathrm{~km}$ along its long axis and approximately $5 \mathrm{~km}$ along its short axis (Rasmussen et al., 2005). The lithology in Kraka varies between pure chalk and marly chalk, with varying amounts of chert layers and nodules. Cores from the field show localized staining which is cyclic and often associated with the chert. On well-scale, three main structural features have been identified in Kraka. Large, open fractures with slickensides are abundantly observed throughout the core data. These fractures commonly terminate in clay rich layers. Smaller, chert-associated fractures occur frequently within the Ekofisk Formation and on occasion within the Tor Formation. Stylolite-associated fractures, which is predominantly observed in 
the Tor formation, are perpendicular to the pressure solution seems and are typically $<25 \mathrm{~mm}$ high.

Both reservoir units are characterized as tight. Porosities are in the range of $20-35 \%$ and permabilities range from $3 \mathrm{mD}$ to $<1 \mathrm{mD}$ (Klinkby et al., 2005). Effective matrix permeabilities in the field are significantly enhanced due to the presence of these natural fractures. The tectonic fractures (shear and extensional) are the main permeability enhancers. Smaller fractures associated with cherts and stylolites may however be important for local permeability enhancement (Jorgensen and Andersen, 1991).

It has previously been concluded that tectonic fracturing in the Kraka chalk may be understood as simple dome related fractures, possibly dominated by a tangential system (Jorgensen and Andersen, 1991). It was also suggested that Kraka fractures occur in swarms: a production logging tool from a horizontal wellbore indicated that only 4 of the 17 perforation intervals in that well contributed $94 \%$ of the fluid production (Jorgensen and Andersen, 1991). The potential existence of fracture swarms is further addressed through our workflow. The results of our data analyses indicate that the Kraka fracture pattern is more complex than previously suggested with a primary set of fractures con-

trolled by the regional maximum horizontal stress as well as a secondary set of dome-related fractures, associated with halokinesis.

\section{Workflow: Data Availability, Consistency and Correlation}

The natural fracture pattern of the Kraka Field was interactively characterized through borehole images (BHIs) and cores, prior to structural correlation with seismic data. The fracture characterization effort was primarily focused on the lateral fracture distribution, as the majority of Kraka wells are horizontal. Main emphasis has been put on the Ekofisk section, as it constitutes the primary target of these wellbores. Seismic was used to map faults and fracture zones away from the borehole and to identify regional structural trends.

The full integrated approach is schematically shown in Figure 2. Specific details of each step are given in the following subsections. 


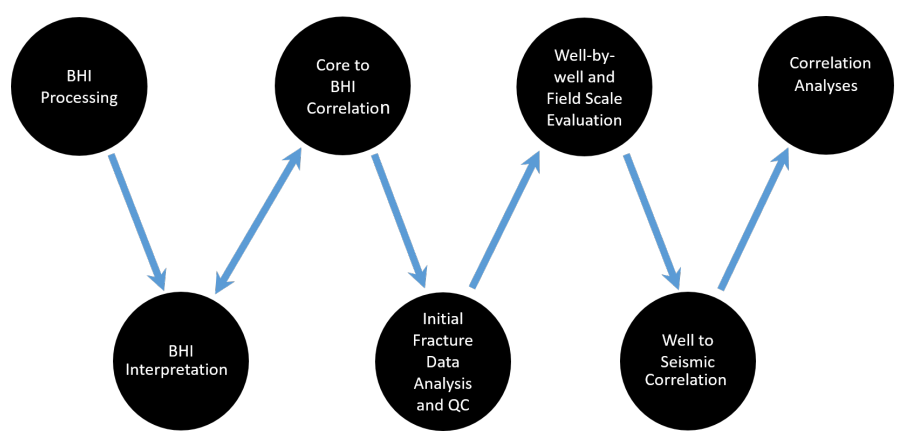

Figure 2: Integrated workflow.

\subsection{BHI Processing}

The applied borehole image data was acquisitioned in wells drilled in the time period between 1989 and 1997. Microresistivity data in Formation MicroScanner (FMS)- or Formation MicroImager (FMI) quality was available in seven wellbores. Three wellbores surveyed by measurement while drilling technology were excluded from this study due to poor data resolution.

In the first step of the workflow, the microresistivity data were manually processed in Techlog, following the Schlumberger standard outline, illustrated in Figure 3.

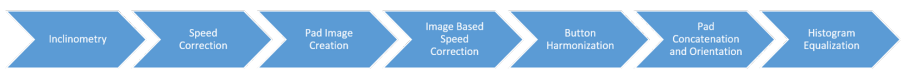

Figure 3: Processing of BHI Data.

Of the wells surveyed by FMS and FMI tools, one is vertical, one is deviated at approximately $70^{\circ}$ at reservoir level and five are horizontal (Table 1).

\begin{tabular}{llll}
\hline Well & Orientation & Tool & Length $(\mathbf{m})$ \\
\hline Well 1 & Horizontal & FMS & 691 \\
Well 2 & Deviated & FMS & 730 \\
Well 3 & Horizontal & FMS & 1987 \\
Well 4 & Horizontal & FMI & 1704 \\
Well 5 & Horizontal & FMI & 2391 \\
Well 6 & Horizontal & FMI & 1681 \\
Well 7 & Vertical & FMI & 205
\end{tabular}

Table 1: Summary of Studied BHI Sections 
Compared to newer image data, the BHIs provided from the Kraka Field are of relatively poor image quality. Moreover, internal image quality variations often occur within single well sections. The latter is largely due to tool sticking, artificial signals and key seating, which is observed in most borehole images from the Kraka Field. Chalk sections directly below chert bands have been particularly hard to resolve, as the chert bands do not have planar surfaces and so cause errors in the pad alignment stage of processing. The cherts, being highly resistive compared to the chalk, are in turn well resolved. Consequently, so are chert associated fractures.

\subsection{BHI Interpretation}

The reservoir chalk is characterized by internal non-planar resistivity contrasts (that are not an expression of bedding features), which may confuse automatic dip-picking algorithms and lead to incorrect picks. All images have therefore been manually interpreted according to dip-picking principles for horizontal wellbores.

The more than 17000 interpreted dip picks were subsequently subjected to structural dip removal (with respect to top reservoir). Alonghole fracture densities were calculated, and then corrected for fracture and wellbore orientation using the Terzaghi correction (Terzaghi, 1965; Peacock et al., 2003). This corrects for the sampling bias due when the fractures are near parallel to the wellbores, and allows us to compare the true density of fracture sets with different orientations. This is important in the case of Kraka since all wells are drilled from a single platform located in the centre of the anticline, and hence form a radial pattern (Figure 4). Moreover four of the seven wells are drilled in a NW-SE direction, perpendicular to the seismically mapped faults. It is therefore essential to compare the true densities of the different fracture sets to determine the main structural controls on fracture orientation. 


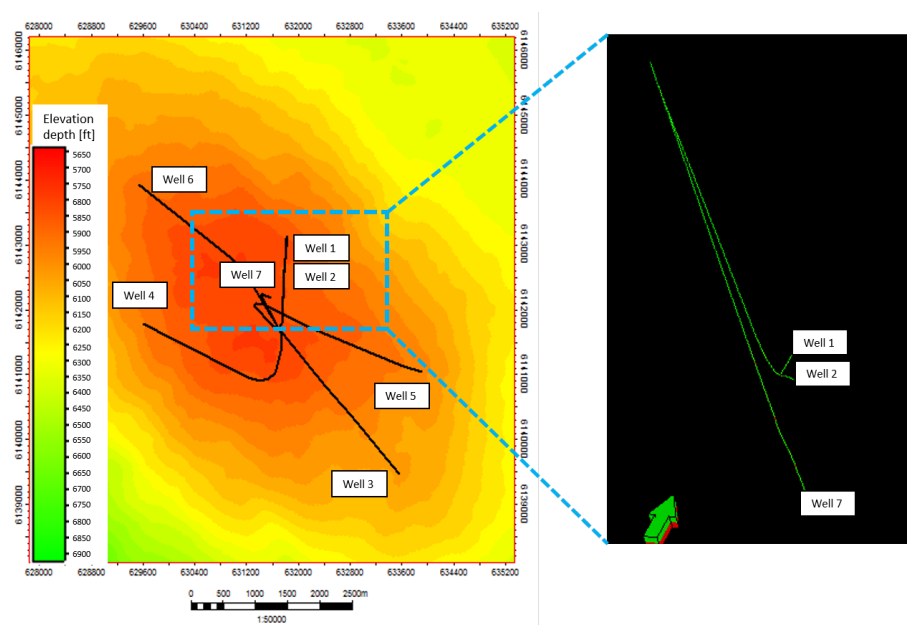

Figure 4: Well pattern of Kraka wells included in this study on top reservoir depth map.

\subsection{Core to BHI Correlation}

The image interpretation scheme was developed through interactive evaluation of core data in the second- and third step of the workflow. Cores were available for three of the BHI-surveyed well sections (wells 1,2 and 7). Depth matching between borehole images and cores was enabled by chert occurrences. Since the cherts are highly resistive compared to the reservoir chalk, they are easily identifiable on BHIs across the field. In the absence of a chert layer or nodule, core-to-log calibration is based on fractures.Depth shifts along wells vary by up to $8 \mathrm{ft}$. Relative fracture orientations measured in core have been reoriented, depth shifted and plotted alongside image fracture-picks in the applied software.

Correlation between borehole images and cores is considered highly advantageous because:

1. BHI and core data are complementary. Borehole images provide true orientations and survey the reservoir in-situ, so we can differentiate open and closed fractures under reservoir conditions. The advantage of core is that we can identify smaller-scale stylolite associated fractures that are not detectable on images because the image resolution is about $1-2 \mathrm{~mm}$.

2. In the BHI data from the Kraka Field, sinusoids representing bedding (chalk and marl) are continuous across borehole images. Most fractures are however only represented by partial sinusoids, either because they are short or because they are only partially open or cemented. Comparison with core data, when available, is imperative in determining which partial signals should be picked. Lessons learned from cored wells are transferable to BHI-surveyed wells without core.

3. In terms of azimuth, the dip-picking tools in the applied software (as in most commercial packages) are highly sensitive to small tweaks. This 
means that the orientation given by tadpoles can change drastically depending on how the partial fracture signal is picked. Where there is ambiguity, we have picked partial sinusoids to be consistent with nearby full sinusoids on borehole images, and calibrated against the fractures in core, where possible.

There is a general good correspondence between orientations of fractures identified in core and fractures picked on borehole images. An example of this is shown in Figure 5, which shows a logged core interval (a) with corresponding $\mathrm{BHI}$ section (b) in the vertical wellbore.

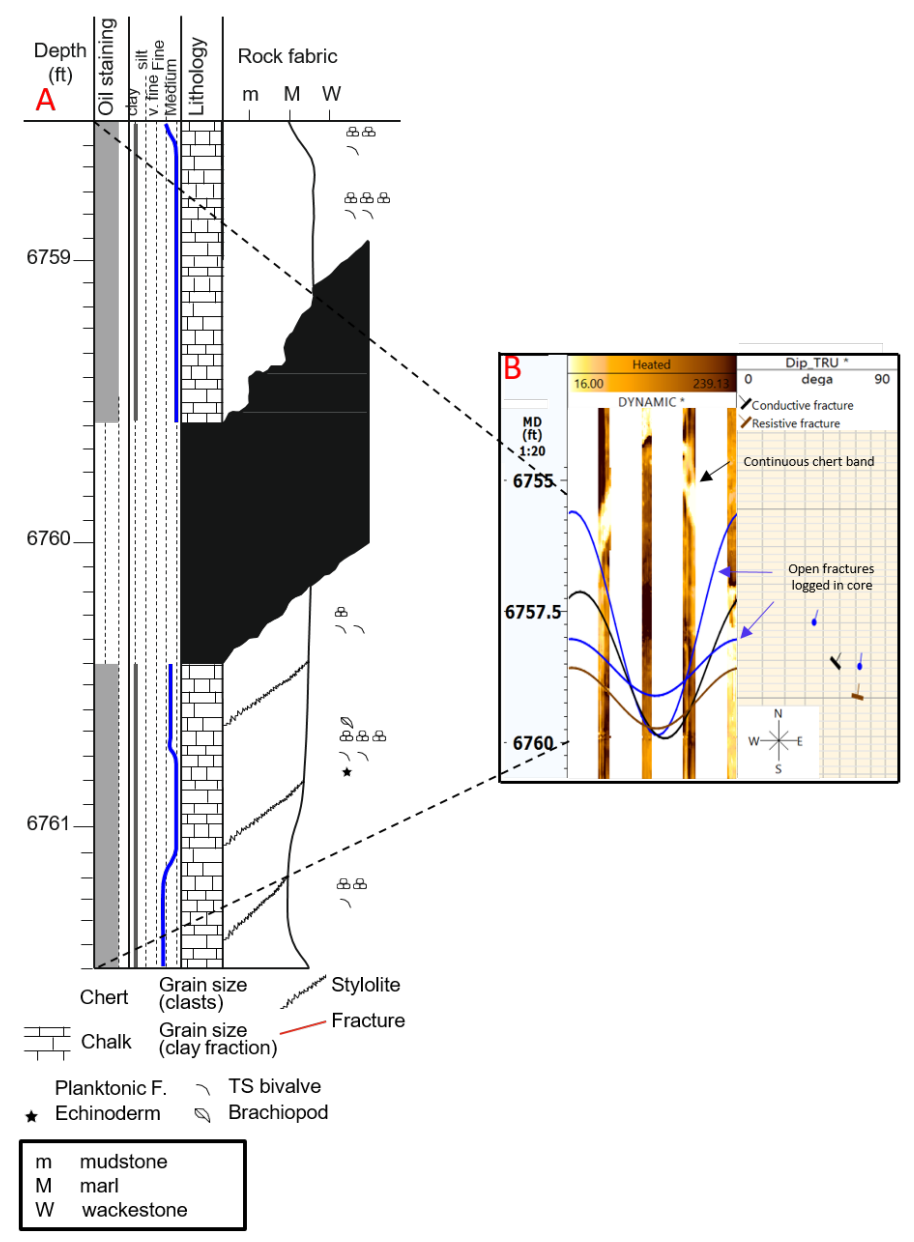

Figure 5: Core log (a) and Core-to-BHI correlation (b) of fractured interval in the vertical wellbore. The core to log shift is approximately $2.5 \mathrm{ft}$, based on the chert band. The section of core shown corresponds to the section of borehole image log from 6756.0-6759.0ft(as indicated by the black stippled lines).

In this case, the core contains two natural fractures, represented by blue tad- 
poles in the borehole image. These are recognised as natural fractures in core by the presence of slickensides. In the core section, both fractures are open. However, the logged fractures coincide with one open (conductive) and one closed (resistive) fracture picked on the image section. Here, the image interpretation is considered reliable as BHIs represent the in-situ reservoir conditions. The closed fracture observed on borehole images could possibly have been opened during the coring process itself. The dip and azimuth of both fractures identified in BHI match the orientation of the fractures logged in core within $12^{\circ}$.

In general, dip angles of core- and BHI fracture picks fit to within $9^{\circ}$ or less, while dip azimuths are associated with a higher degree of uncertainty. Small discrepancies are to be expected, as core must be reoriented manually to calculate true orientations. Therefore fracture orientations from BHIs are considered the most reliable, while the presence and type of fractures can be identified in the core.

Core-fracture densities are $44 \%$ and $36 \%$ higher than BHI-fracture densities in wells 1 and 2, respectively (Figure 6). Stylolite occurrences in the chalk accounts for some of the disparity, as they are not resolved in the images. Moreover, fractures located in bioturbated zones and well-parallel fractures are difficult to distinguish in the BHIs. The remaining discrepancy is linked to the quality and resolution of images. The fracture density percentage for well 7 has not been computed, as there are few data points to compare.

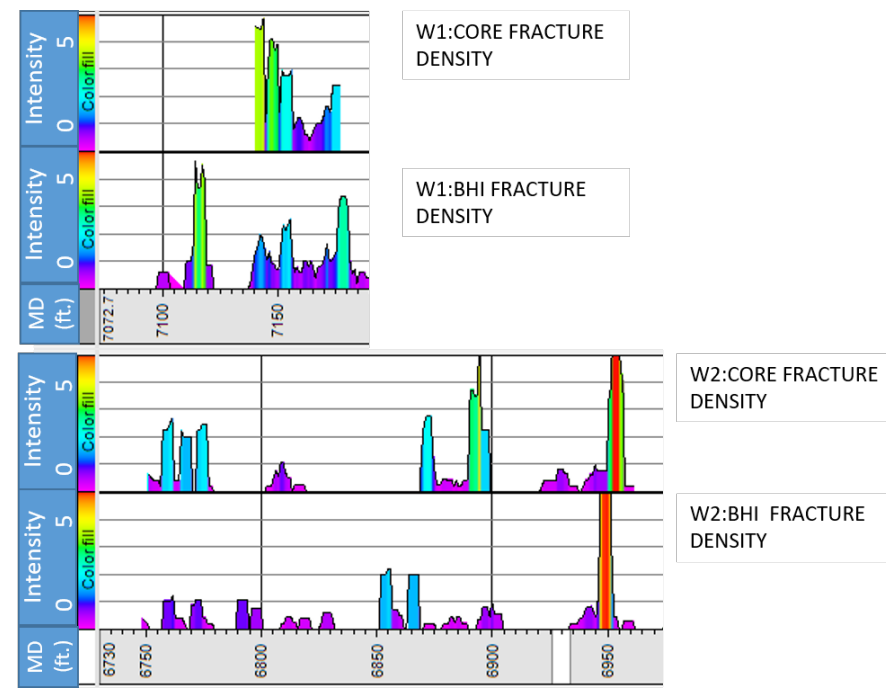

Figure 6: Corrected fracture intensity logs of core-fractures and BHI-fractures in the cored intervals of wells 1 and 2 (scale 1:700). Fracture densities range from 0 in purple to 5 in red. 


\subsection{Initial Fracture Data Analysis and $Q C$}

The true orientations of the fracture picks in each well were plotted on upper hemisphere stereonets, and these were used to classify fractures into sets on the basis of orientation. The fracture strikes were then plotted on rose diagrams drawn over the stereonets, after applying the Terzaghi correction, to enable direct comparison of the fracture densities in the different sets, on a well by well basis.

\subsection{Well-by-well and Field Scale Evaluation}

Alonghole fracture density logs were generated, with Terzaghi correction applied to individual fractures, to study the spatial distribution of fractures, and determine qualitatively whether they are clustered or evenly distributed. More quantitative analysis of the fracture distribution was carried out using cumulative density distribution plots, and by calculating the coefficient of variation of fracture spacing.

The cumulative fracture spacing distribution can be plotted by measuring the distance between each pair of adjacent fractures along a wellbore (without correcting for orientation), ranking them in order, and plotting the results on a cumulative density distribution diagram. The cumulative density distribution with respect to fracture spacing is analogous to the cumulative density distribution with respect to fracture displacement or fracture length (see e.g. Marrett and Allmendinger, 1991, 1992; Westaway, 1994; Marrett, 1996): a straight line on a log-linear plot indicates a random fracture distribution (Olson et al., 2001), while a straight line on a log-log plot indicates a power law distribution with clustering of fractures and may indicate fracture swarms (Gillespie et al., 1993, 2001).

The coefficient of variation of fracture spacing Cox and Lewis (1966) provides a more straightforward method to quantify the degree of clustering. The coefficient of variation $\mathrm{R}$ is defined as the standard deviation of fracture spacing divided by the mean fracture spacing:

$$
R=\frac{\text { Standard deviation of fracture spacing }}{\text { Mean fracture spacing }}
$$

A ratio $\mathrm{R}>1$ implies fracture clustering and the presence of swarms. A ratio of $\mathrm{R}=1$ implies a random fracture distribution $\mathrm{A}$ ratio of $\mathrm{R}<1$ implies regularly spacing fractures.

The fracture distribution can tell us something about the mechanisms of fracture formation. In particular a clustered fracture distribution often develops when the stress anomaly develops around the tip of a propagating fracture, promoting the growth of nearby fractures, in a similar manner to the process 
zone often observed around igneous dykes (Olson, 2003). A modelling study by Olson (2004) shows that this is often the result of critical fracture propagation in a brittle material.

\subsection{Well to Seismic Correlation}

Fracture picks from BHIs and cores were subsequently compared to a structural framework derived from the amplitude seismic volume, provided by Maersk, as well as to two ant-tracked structural models in step 6 of the workflow. The seismic amplitude cube (in depth), acquired in 2012, has a vertical resolution in the order of $40 \mathrm{~m}$ (sampling rate of $4 \mathrm{~ms}$ ). The ant-tracked volumes enhance subtle faults and fracture zones that are below this vertical resolution. The ant-tracking algorithm systematically analyzes a seismic input cube mimicking the swarm intelligence of ants (Pedersen et al., 2002). Here, a large number of agents (ants) are distributed in the volume. Each ant propagating through the cube is programmed to detect continuous structural lineations. Confidence levels are assigned depending on the length and width of the path of segments.

The first ant-tracked volume was generated in Petrel according to the following procedure (Figure 7):

1. Cropped the original amplitude cube to speed up calculation.

2. Generated a structural smoothing/median filter cube to increase horizontal continuity and to pick out the more consistent structural features. The optimal degree of smoothing was achieved through adjusting the attribute parameter and observing its effect on the smoothing cube (in real time) prior to realization.

3. Extracted the variance/chaos cube from the smoothing cube to highlight discontinuities. The variance cube software is based on wavelet analysis. It calculates the direct measurement of dissimilarity rather than the inferred similarity of seismic data, producing sharper, more distinct results than those with traditional coherency techniques (Schlumberger, 2006).

4. Ran ant-tracking algorithm to enhance discontinuities.

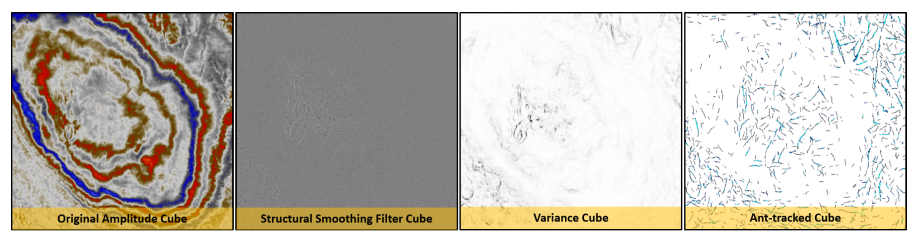

Figure 7: Workflow for generating ant-tracked volume from the seismic depth cube of the Kraka Field in Petrel.

The second ant-tracked volume was generated in eXchroma and Petrel according to the following procedure: 
1. Cropped the original amplitude cube to speed up calculation.

2. Applied the structurally sharpened red-green-blue method, which uses the simultaneous rendering of multiple depth slices in continuous RGB color to highlight geophysical heterogeneities representative of geologic features, to the amplitude cube (Laake, 2015). The result is an image processed photo-style cube.

3. Ran ant-tracking algorithm to enhance discontinuities.

The vertical resolution of the wavelet based ant-tracked volume is $24 \mathrm{~ms}$ ( 7 times the sampling rate). In the RGB ant-tracked cube, the vertical resolution is $12 \mathrm{~ms}$ ( 3 times the sampling rate). The latter cube has therefore been preferentially used in this study (Figure 8).

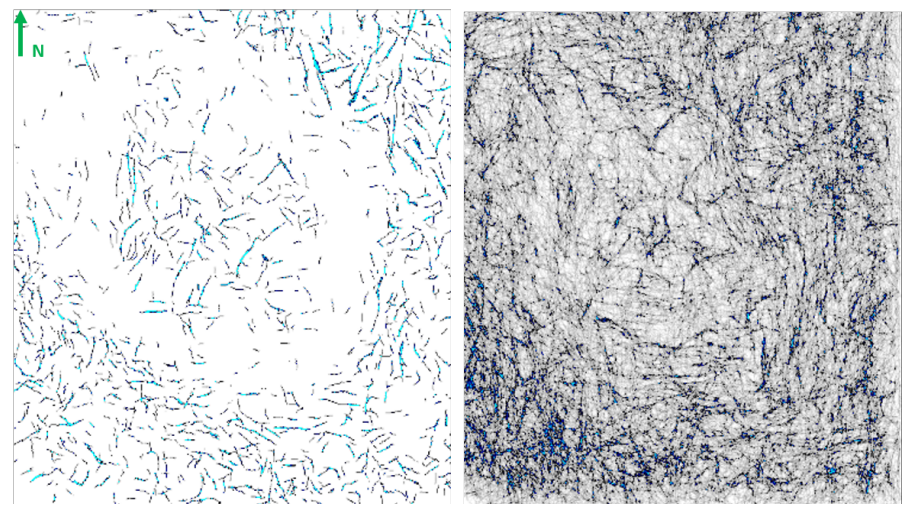

Figure 8: Comparison of the wavelet-based (left) and the RGB-based (right) ant-tracked volumes.

\subsection{Correlation Analyses}

The interpretation of structural features along the well bore on seismic scale was carried out on an opacity mix of the ant-tracked volume and the seismic amplitudes (Figure 9). This mixed view enables a focused interpretation of localized features in the seismic data. Also, we avoid misclassification of noise or acquisition artifacts. The opacity of the ant-track overlay was adjusted dynamically to enable the best interpretation possible.

The structural interpretation of the seismic data was done independently from the fracture interpretation of the BHIs. This reduces bias in the interpretation and "correlation finding" when looking at mixed displays. "Correlation finding" is a bias in interpretive science, where the interpreter has both displays open and finds feature in one display because they know to expect a feature from the other display. 
Dip- and azimuth values were averaged along the fault planes of each interpreted fault to allow for direct comparison with well-scale data in upper hemisphere stereonet projections in the seventh- and final step of the workflow.

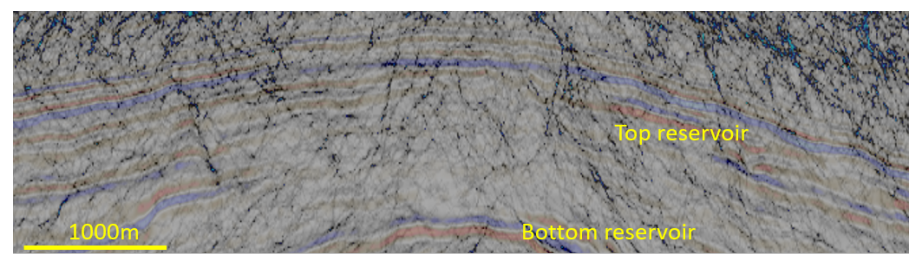

Figure 9: Amplitude-cube over the Kraka Field with the RGB volume as opaque overlay, used for seismic interpretation 


\section{Workflow Outcomes: Well-scale Fracture Trends}

\subsection{Fracture Densities and Fracture Swarms}

Figure 10 shows the fracture orientations in the four NW-SE oriented horizontal wells prior to- and after applying the Terzaghi correction for borehole orientation. According to expectations, the rose diagrams for uncorrected fracture strike are dominated by NE-SW striking fractures, as fractures in this orientation will be preferentially intersected by the boreholes. After correcting for orientation, however, the rose diagrams largely remain unchanged, indicating that this reflects a real preferred fracture orientation, and not just bias due to well orientation. However in two of the wells (wells 3 and 4), the Terzaghi correction also reveals another fracture set, striking NW-SE, that cannot be identified on the uncorrected data. This suggests that multiple intersecting fracture sets are present in these locations, as well as demonstrating that the Terzaghi correction is correctly revealing the true preferred fracture orientations.
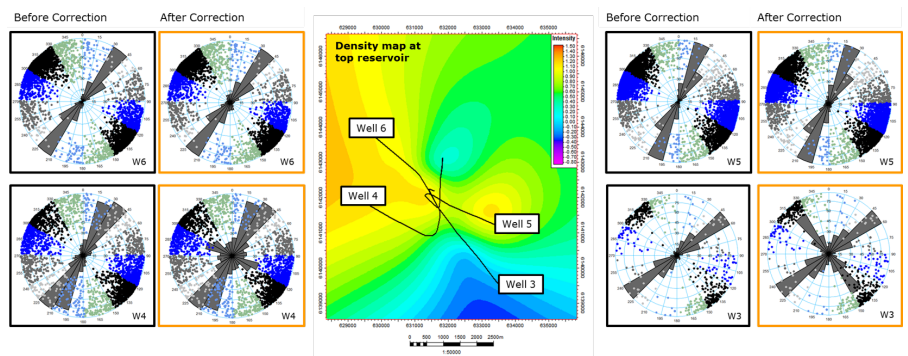

Figure 10: Uncorrected and Terzaghi-corrected strike-rose diagrams from NW-SE oriented wells. Note that the fracture pole data, shown as dots on the stereonets (upper hemisphere), is uncorrected in both instances.

The uncorrected fracture orientations from the two wells oriented approximately north-south also show a majority of the fractures striking east-west (Figure 11). In these wells, however, correction for wellbore orientation significantly reduces the relative importance of this fracture set, and reveals that the dominant fracture trend strikes north-south, parallel to the wellbores (although there is still a population of east-west fractures, so this location is likely to be characterised by multiple intersecting fracture sets). 

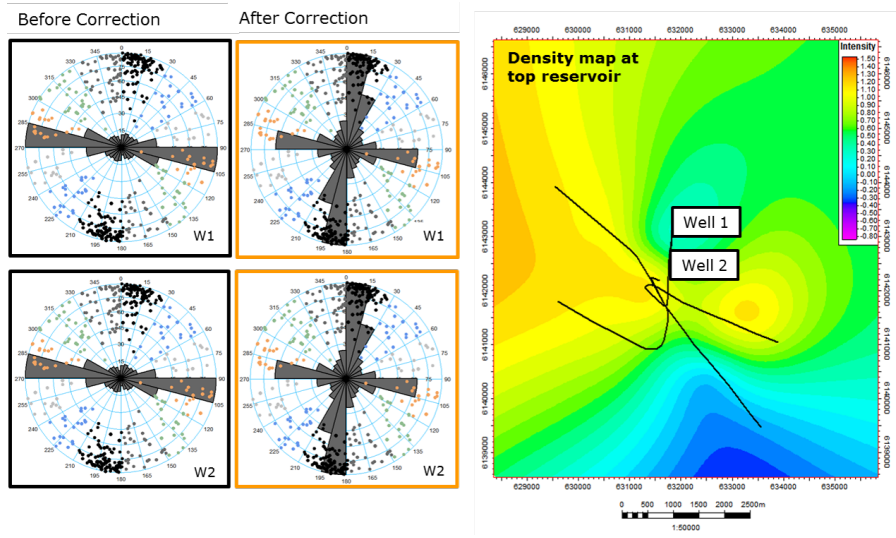

Figure 11: Uncorrected and Terzaghi-corrected strike-rose diagrams from N-S oriented wells. Note that the fracture point data, shown in the stereonets (upper hemisphere), is uncorrected in both instances.

In the Terzaghi-corrected fracture intensity logs from the seven wellbores, the fracture density and distribution varies between wellbores (Figure 12). Relatively high and uniform fracture densities are observed in wells 4, 5 and 6 . Mean fracture densities are lower in wells 1, 2 and 3, but the fractures in these wells appear more clustered, with potential fracture swarms observed. The highest fracture density is found in the vertical well 7 and the lowest fracture density occurs in the horizontal well 3.

The fracture distribution was investigated quantitatively by plotting cumulative density distribution plots for fracture spacing, and calculating the coefficient of variation for the fracture spacing in each well. Results were relatively consistent between all investigated wells. Generally, smaller fracture spacings (0.1-10ft) follow a straight line on the log-log plot, indicating a close-to Power law distribution, while larger spacings (more than 10ft) follow a straight line on the log-linear plot, indicating a close-to random distribution (Figure 13). We can also see a clear distinction between wells 1,2 and 3 , characterised by high overall fracture densities (they intersect the y axis at high values) and high power law exponents (steep density distribution curves), and wells 4, 5, and 6, characterised by low overall fracture densities and low power law exponents. 

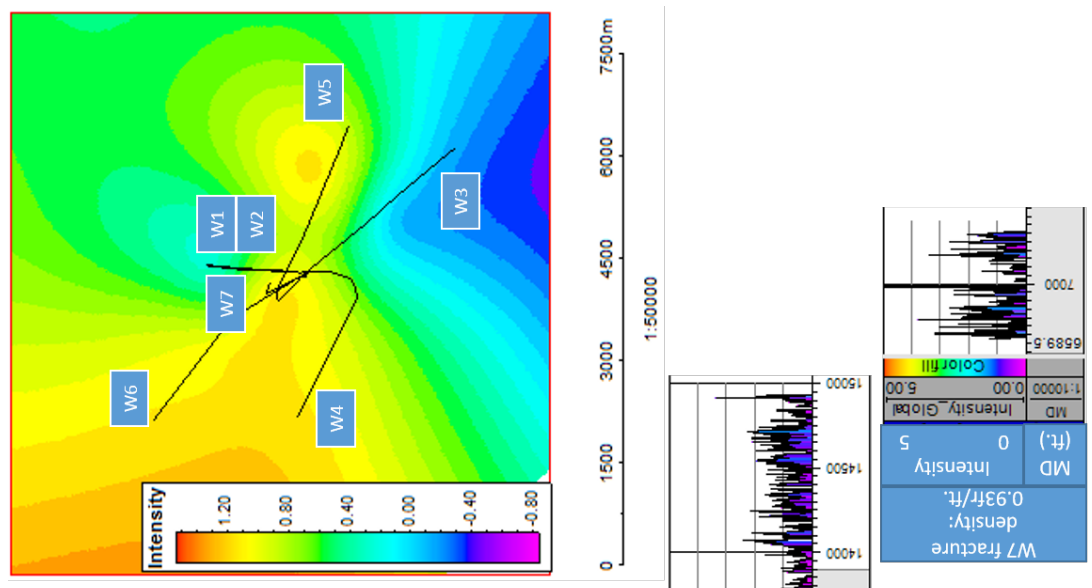

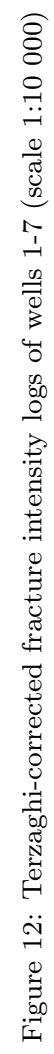
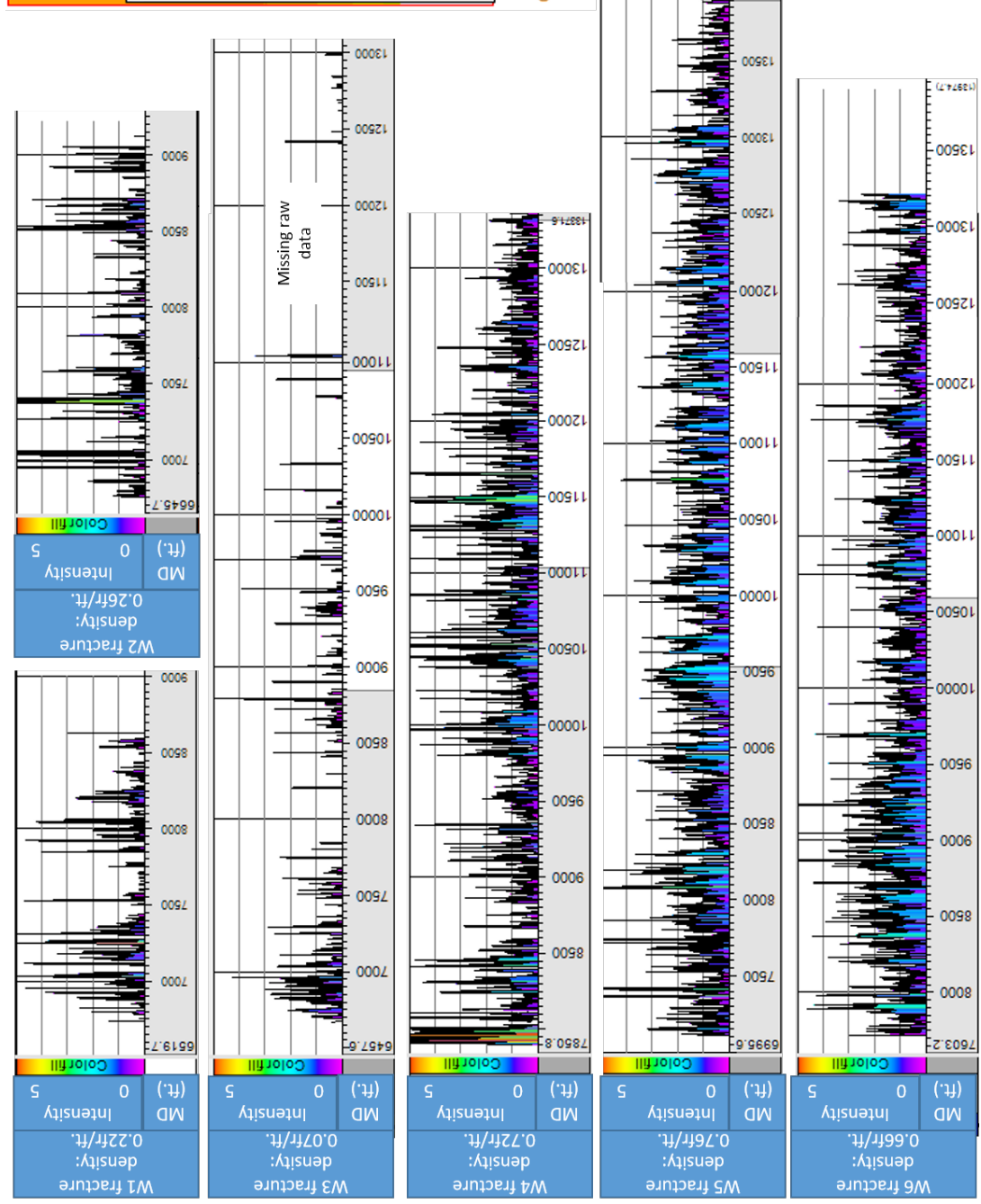

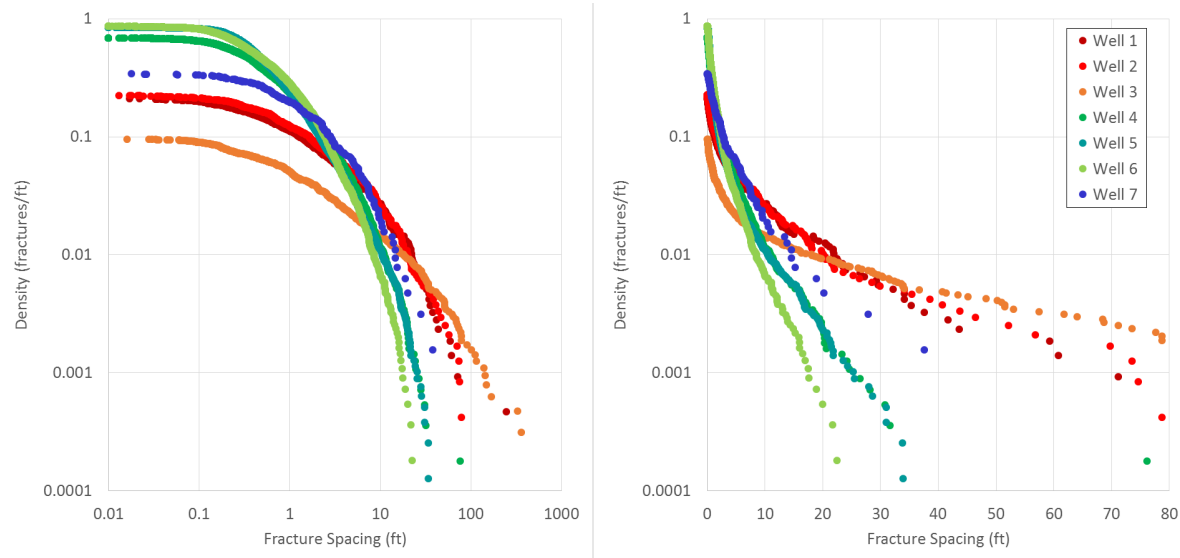

Figure 13: Fracture spacing distributions for the seven Kraka wells, shown on a log-log plot (left) and log-linear plot (right).

The values of the mean, standard deviation and coefficient of variation $\mathrm{R}$ for the fracture spacings in each well are summarized in Table 2. In case of a clustered Power law distribution, the standard deviation should be smaller than the mean, so $\mathrm{R}>1$. In a perfectly random distribution, the standard deviation equals the mean, so $\mathrm{R}=1$.

\begin{tabular}{llll}
\hline Well & $\sigma$ & $\mu$ & $R$ \\
\hline Well 1 & 8.3 & 4.2 & 2.0 \\
Well 2 & 9.2 & 4.4 & 2.0 \\
Well 3 & 21.4 & 7.2 & 3.0 \\
Well 4 & 2.7 & 1.4 & 1.9 \\
Well 5 & 2.2 & 1.2 & 1.9 \\
Well 6 & 1.7 & 1.1 & 1.5 \\
Well 7 & 4.5 & 2.9 & 1.5
\end{tabular}

Table 2: Standard deviations $\sigma$, mean values $\mu$, and coefficient of variation $R$ of the fracture spacing data from the seven Kraka wells.

This data confirms the observations from the fracture intensity plots. The mean fracture spacing is much higher in wells 1, 2 and 3 than in wells 4,5 and 6 , indicating a lower fracture density. As the coefficient of variation $\mathrm{R}>1$ in all wells, some clustering of the fractures occurs in all Kraka wells, but the distribution in wells 1,2 , and 3 is more clustered than in wells 4,5 and 6 . However the coefficient of variation $\mathrm{R}$ is still quite low in most wells (and is not much higher in wells 1 and 2 than in wells 4 and 5), suggesting a significant random 
component in the distribution of fractures in all wells. The greatest clustering occurs in well 3 , which is the well with the lowest fracture density, i.e. the highest mean spacing.

The fracture distribution and the coefficient of variation in vertical well 7 is in good correspondence with that observed in the horizontal wells. This suggests a fairly isotropic fracture distribution in Kraka. However, this inference is based on just one horizontal well, and must therefore be treated with caution.

\subsection{Fracture Sets}

The majority of fractures observed are steeply dipping: $0.24 \%$ of the BHIfractures are shallow dipping $\left(<30^{\circ}\right), 24.62 \%$ of the fractures have intermediate dip values $\left(30-70^{\circ}\right)$ and $75.14 \%$ are steep $\left(70-90^{\circ}\right)$ (although these figures are not corrected for orientation relative to the wellbores).

Figure 14 shows upper hemisphere stereonets and orientation-corrected rose diagrams for the fracture data from each well, broken down by stratigraphic unit. Data from the Danian Ekofisk formation is highlighted in green, and data from the Maastrichtian Tor formation is highlighted in red.

We have identified two main fracture trends in the Danian Ekofisk section. The first is a dominant NE/NNE trending regional fracture set, which strikes parallel or near-parallel to the maximum horizontal stress in the area. This main fracture trend is present in the Ekofisk intervals of all horizontal/deviated wellbores and has been confirmed by core data (from wells 1 and 2). Due to data constraints, the vertical fracture distribution of the Kraka Field was primarily studied in well 7 . Although the data foundation is insufficient, results from this well indicate that the dominant NE/NNE trend of the Ekofisk formation is vertically continuous.

The secondary fracture set consists of fractures striking parallel and perpendicular to the contours of the Kraka Dome. The orientation of these fractures varies between wells, depending on their location on the dome. This fracture set is thought to have formed during salt movements, and it is expected to follow the strain evolution of the Kraka chalk. Because of the positions of wells 5 and 6 , the two fracture sets in cannot be distinguished on the basis of orientation in these wells (the dome contours are parallel to the NE/NNE regional trend).

The NNE/NE trending regional fracture set continues into the Tor Formation of wells 2, 6 and 7. However there is much more scatter in the Tor orientation data than in the Ekofisk data. The scattering may be due to varying local stresses during salt movements, however there is insufficient data from the Tor Formation to determine the fracture pattern with confidence. 


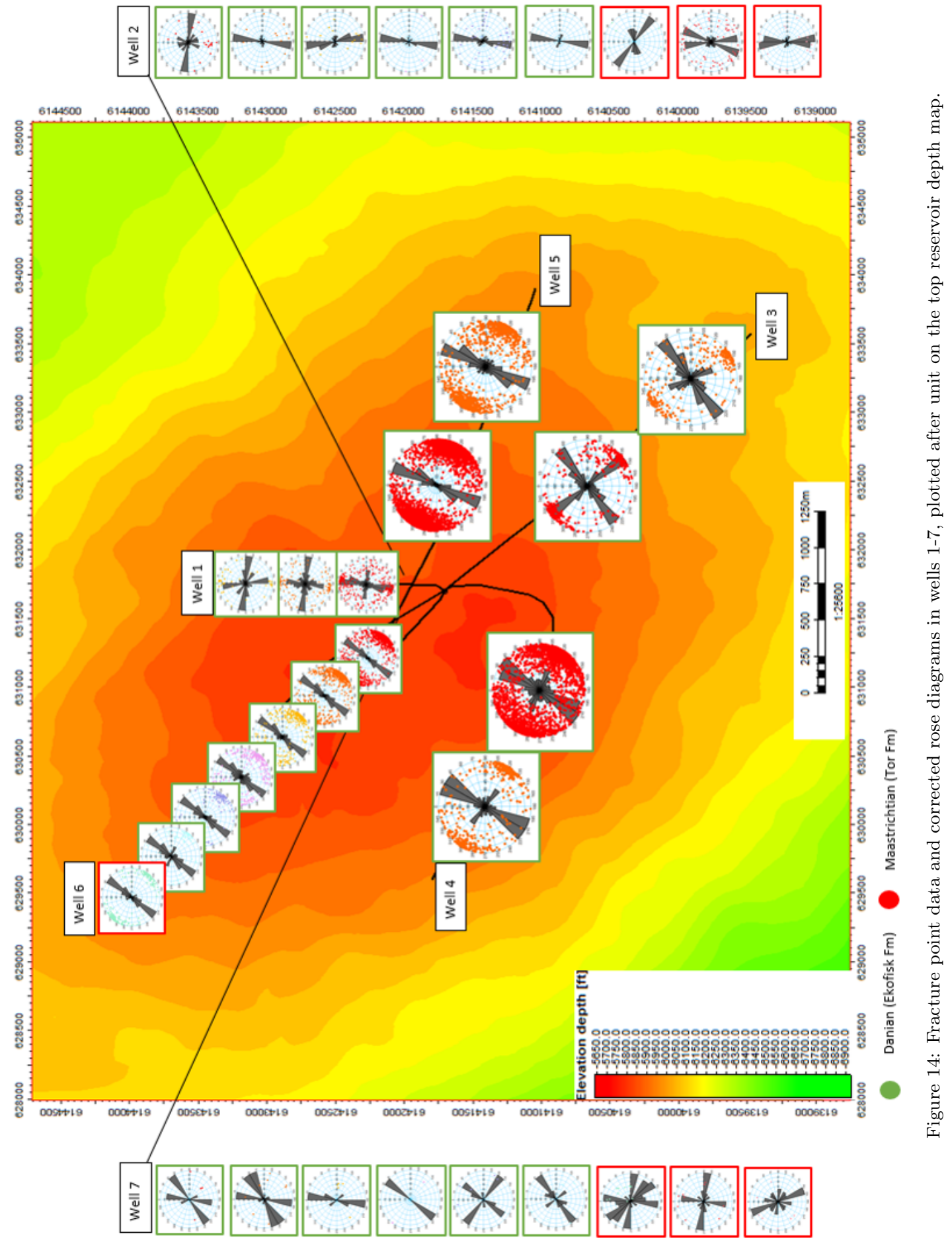




\section{Workflow Outcomes: Seismic-scale Fault Trends}

The orientation data for the lineations observed on RGB ant-tracked seismic data, and for the large-scale faults interpreted on amplitude seismic are shown in figure 15. The ant-tracked structural model contains 25 lineations along the well trajectory. The majority (16) of these lineations strike NNE/NE. Of the 32 large-scale faults interpreted on amplitude seismic, 18 are oriented in a NE direction, while only 3 faults strike NNW. This indicates that the NNE trend is representative for smaller-scale lineations, at the limit of resolution of amplitude seismic. The rose diagram for the ant-tracked lineations shows higher variance than the large-scale faults. This implies greater variation in the orientation of small scale features in comparison to large-scale fault trends, which we would expect.
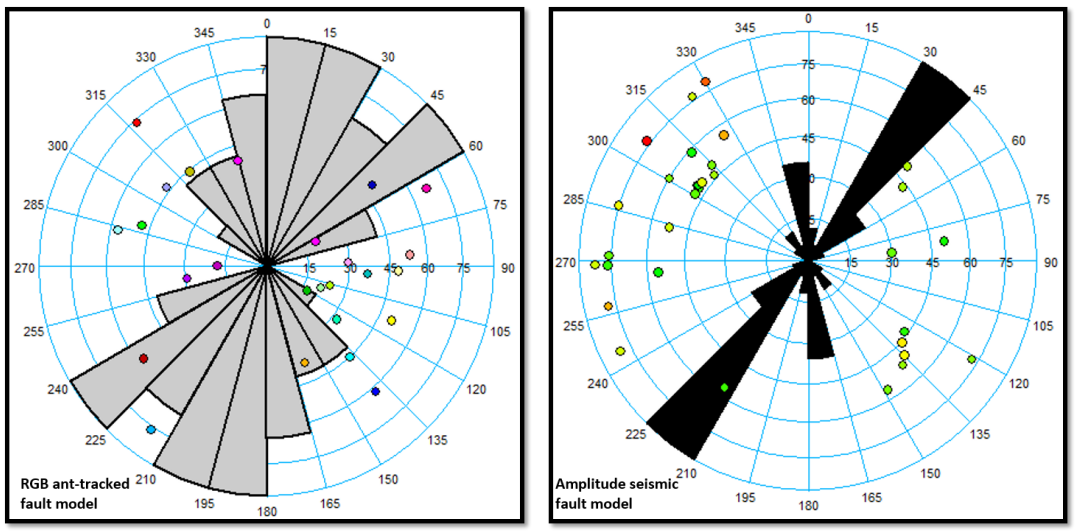

Figure 15: Rose diagrams of structural lineations interpreted on the RGB ant-tracked volume (left) and the amplitude volume (right).

Overall the NE/NNE trend of the lineations and the large-scale faults matches the orientation of one of the main sets of fractures observed on borehole images. The main NE/NNE fracture trend can therefore be correlated from wellborescale fractures to local lineation scale and to field-wide fault scale (compare figure 14 and figure 15). This suggests that many of the wellbore-scale fractures are genetically related to the seismic-scale faults, and formed in response to a regional stress regime. The resulting fracture and fault set covers a range of scales, from small fractures with lengths $¡ 1 \mathrm{~m}$ up to seismic-scale faults with lengths of several $\mathrm{km}$. The increased variance in orientation of the small-scale features may be partly due to uncertainty of the interpretation, and partly due to small-scale local variations in stress regime, for example around larger faults or around the salt diapir.

There are of course many more fractures observed on borehole images than lineaments observed on the RGB ant-tracked seismic data, and most of the in- 
dividual fractures observed on the borehole images are of a much smaller scale than the lineaments. There is therefore no direct correspondence between fractures on borehole images and lineaments observed on the ant-tracked seismic data. Nor do we see a clear correlation between the density of fractures on borehole images and the location of the lineaments (figure 16). This may partly reflect variation in borehole image quality: it was not possible to pick so many fractures in areas of poor image quality.

However, if we filter the fractures from borehole images to only include the resistive fractures, we do see a clear correlation in many wells, between both the distribution and the orientation of resistive fractures and the seismic lineaments. This is particularly clear for the NW-SE oriented horizontal wells $3,4,5$ and 6 (figure 17). This suggests that the resistive fractures observed on borehole images may be more likely to represent or be associated with larger-scale structures than the conductive fractures. This is quite plausible, as resistive fractures are filled with some resistive material, which may be fault gouge or cement precipitated from a fluid travelling through the fracture. Thus we would expect faults with significant displacement, or fractures associated with such small faults (e.g. in the damage zone), to appear as resistive fractures on borehole images. Conductive fractures, by contrast, could mostly represent a distributed background population of small, unfilled cracks. 


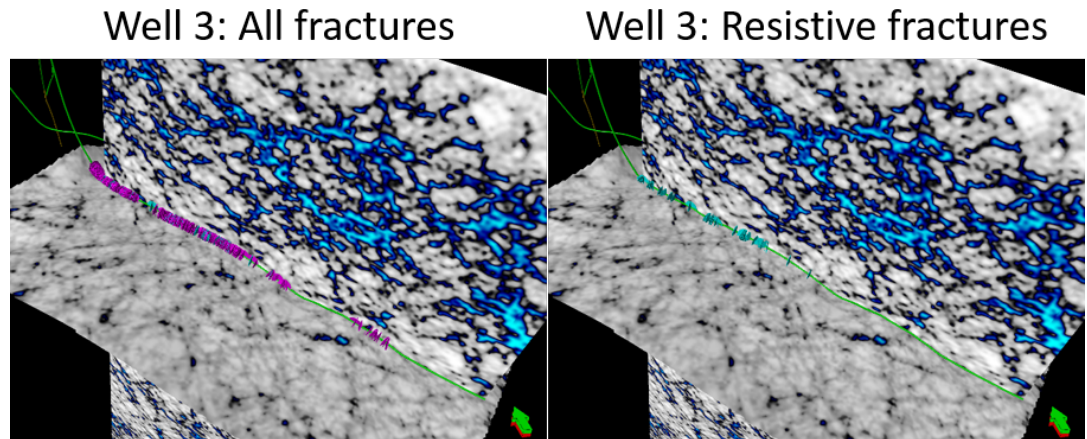

Well 6: All fractures

Well 6: Resistive fractures

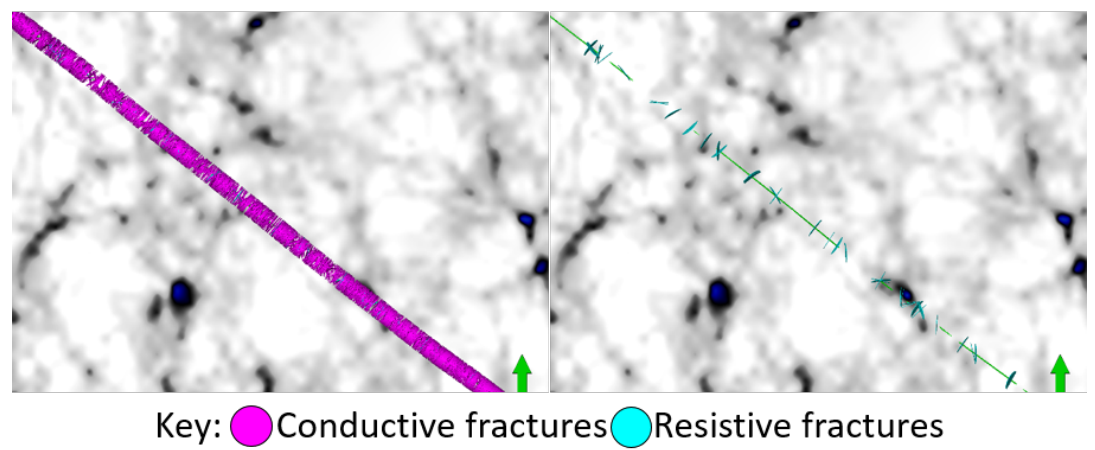

Figure 16: Comparison of fractures interpreted on borehole images, shown by coloured disks, and lineations observed on RGB ant-tracked seismic data, for wells 3 and 6 . The left hand pictures show all fractures interpreted on borehole images, with conductive fractures shown by pink disks and resistive fractures by blue disks, while the right hand pictures show only the resistive fractures. 
Well 3: Resistive fractures Well 4: Resistive fractures
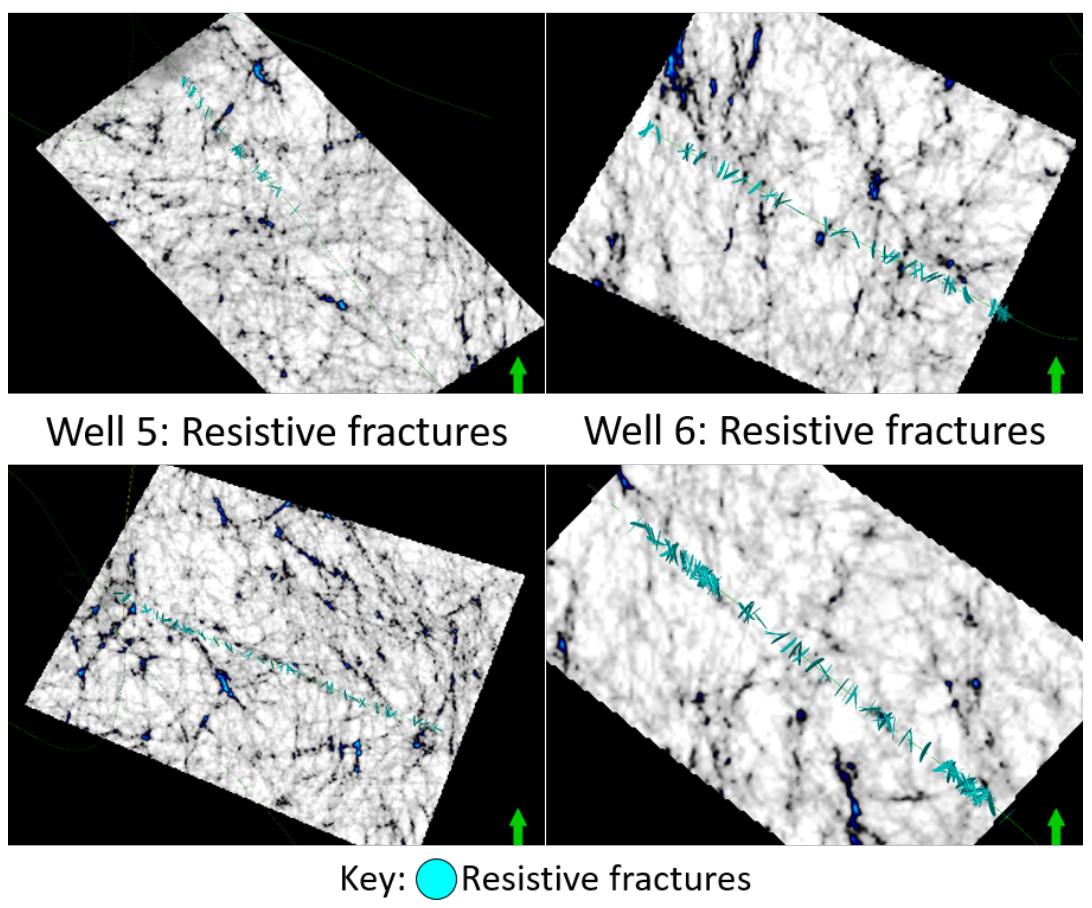

Figure 17: Comparison of the resistive fractures interpreted on borehole images, shown by blue disks, and lineations observed on RGB ant-tracked seismic data, for wells 3, 4, 5 and 6 . All wells are shown looking down from above. 


\section{Summary and Conclusions}

We have established an integrated workflow for correlation of structural features at different scales in chalk reservoirs. The workflow bridges the scale-gap between well-scale and seismic data sets, and has increased our understanding of the natural fracture system in our test case, Kraka. Such knowledge can be used strategically in optimizing production schemes and obtaining sustainable recovery factors. The combination of BHI- core- and seismic data allow for the extrapolation of fractures away from the borehole.

An obvious next step in this workflow is upscaling, fracture modelling and evaluation of current findings through fluid simulations. Such simulations, verified through production data, might provide feedback to the fracture characterization effort, further improving the model (closed loop).

Application of our approach in the Kraka Field indicate that:

1. A large portion of extensional and chert-associated fractures identified in core are distinguishable in borehole images. Stylolites, stylolite-associated fractures, fractures located in bioturbated zones and well-parallel fractures are however difficult to differentiate in the BHIs.

2. Borehole images are imperative in distinguishing cemented from open fractures, as as cemented fractures may be opened during the coring process. BHIs thus increase our ability to constrain fluid flow along the fracture network.

3. Extensional and chert-associated fractures are commonly represented by partial sinusoids in BHIs, suggesting they are either short or only partially open or cemented.

4. Manual dip-picking was deemed requisite because of:

- The large portion of fractures represented by partial sinusoids.

- Relativley poor image quality (compared to to newer BHI data).

- Internal resistivity variations, which may confuse automatic dip-picking tools.

5. For the ant-tracked algorithm, higher vertical resolution can be achieved through RGB image processing, compared to wavelet based extraction of structural features. Both ant-tracked volumes display structural trends that are below the resolution of amplitude seismic.

6. Fractures picked on BHIs correlate to large-scale regional trends and to features picked on ant-tracked seismic data. This strengthens the case of a consistent regional stress field that scales down to local stresses observed at the BHI and core scale. We can therefore extrapolate fractures away from the wellbores and calibrate 3D models (e.g. discrete fracture network models).

In our test case, the results of the workflow show that the Ekofisk Formation of the Kraka Field is characterized by steep fractures striking NE and NNE, parallel or near-parallel to the maximum horizontal stress in the area. Fractures in 
Kraka occur as swarms and as isolated features. Moderate fracture clustering occurs in the majority of horizontal wells, as well as in the vertical well. The greatest tendency for fracture swarm occurrence is observed in the horizontal well with the lowest associated fracture density.

The main fracture trend, established from borehole images and core, is present in the Ekofisk sections of all horizontal/deviated wellbores and has been confirmed by core data. Results from the vertical well 7 indicate that the dominant NE/NNE trend of the Ekofisk Formation is vertically continuous. A secondary fracture set of fractures striking parallel and perpendicular to the contours of the Kraka Dome was identified. The orientation of these fractures varies between wells, depending on their location on the dome. This fracture set likely developed during salt movements and is expected to follow the strain evolution of the Kraka chalk.

The main NNE/NE fracture trend can be correlated from well scale to anttracked scale. Faults mapped on amplitude seismics can also be identified in the ant-tracked cube. In the amplitude model, faults mainly trend NE, indicating that the NNE trend is representative for smaller-scale lineations (well scale to ant-tracked scale).

This integrated study proves invaluable in testing assumptions in building fracture models and the subsequent upscaling process and will be useful for validating a geomechanically based DFN for the Kraka Field.

\section{Acknowledgements}

The research leading to these results has received funding from the Danish Hydrocarbon Research and Technology Centre under the Advanced Water Flooding programme.

We thank DUC for providing data access and F. Amour for his useful input . We would also like to extend our thanks to Schlumberger for providing licenses for Petrel, eXchroma and Techlog.

\section{References}

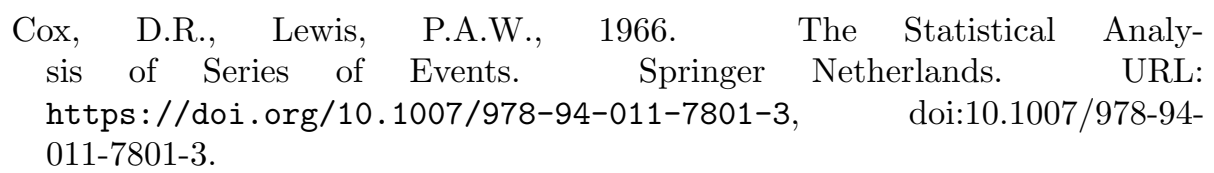

Fernø, M.A., 2012. Enhanced oil recovery in fractured reservoirs, in: Introduction to Enhanced Oil Recovery (EOR) Processes and Bioremediation of 
Oil-Contaminated Sites. InTech. URL: https://doi.org/10.5772/34732, doi: $10.5772 / 34732$.

Gillespie, P., Howard, C., Walsh, J., Watterson, J., 1993. Measurement and characterisation of spatial distributions of fractures. Tectonophysics 226, 113-141. URL: https://doi.org/10.1016/0040-1951(93)90114-y, doi:10.1016/0040-1951(93)90114-y.

Gillespie, P., Walsh, J., Watterson, J., Bonson, C., Manzocchi, T., 2001. Scaling relationships of joint and vein arrays from the burren, co. clare, ireland. Journal of Structural Geology 23, 183-201. URL: https://doi.org/10.1016/s0191-8141(00)00090-0, doi:10.1016/s0191-8141(00)00090-0.

Jorgensen, L., Andersen, P., 1991. Integrated study of the kraka field, in: Offshore Europe, Society of Petroleum Engineers. URL: https://doi .org/10.2118/23082-ms, doi:10.2118/23082-ms.

Klinkby, L., Kristensen, L., Nielsen, E.B., Zinck-Jørgensen, K., Stemmerik, L., 2005. Mapping and characterization of thin chalk reservoirs using data integration: the kraka field, danish north sea. Petroleum Geoscience 11, 113124. URL: https : //doi .org/10.1144/1354-079304-632, doi:10.1144/1354079304-632.

Koestler, A., Reksten, K., 1992. Insight into the 3d fracture network of an exposed analogue of fractured chalk reservoirsthe lägerdorf case, in: Proc. Fourth North Sea Chalk Symposium.

Laake, A., 2015. Structural interpretation in color - a new RGB processing application for seismic data. Interpretation 3, SC1-SC8. URL: https://doi .org/10.1190/int-2014-0041.1, doi:10.1190/int-2014-0041.1.

Marrett, R., 1996. Aggregate properties of fracture populations. Journal of Structural Geology 18, 169-178. URL: https://doi.org/10.1016/s0191-8141(96)80042-3, doi:10.1016/s01918141(96)80042-3.

Marrett, R., Allmendinger, R.W., 1991. Estimates of strain due to brittle faulting: sampling of fault populations. Journal of Structural Geology 13, 735-738. URL: https://doi.org/10.1016/0191-8141(91)90034-g, doi:10.1016/0191-8141(91)90034-g.

Marrett, R., Allmendinger, R.W., 1992. Amount of extension on "small" faults: An example from the viking graben. Geology 20, 47. URL: https ://doi .org/10.1130/0091-7613(1992) 020<0047:aoeosf >2.3.co;2,

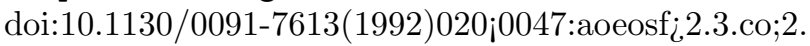

Møller, J.J., Rasmussen, E.S., 2003. Middle jurassic-early cretaceous rifting of the danish central graben. The Jurassic of Denmark and Greenland. Geological Survey of Denmark and Greenland Bulletin 1, 247-264. 
Olson, J.E., 2003. Sublinear scaling of fracture aperture versus length: An exception or the rule? Journal of Geophysical Research: Solid Earth 108. URL: https://doi.org/10.1029/2001jb000419, doi:10.1029/2001jb000419.

Olson, J.E., 2004. Predicting fracture swarmsthe influence of subcritical crack growth and the crack-tip process zone on joint spacing in rock. Geological Society, London, Special Publications 231, 73-88. URL: https://doi.org/10.1144/GSL.SP.2004.231.01.05, doi:10.1144/GSL.SP.2004.231.01.05.

Olson, J.E., Yuan, Q., Holder, J., Rijken, P., 2001. Constraining the spatial distribution of fracture networks in naturally fractured reservoirs using fracture mechanics and core measurements, in: SPE Annual Technical Conference and Exhibition, Society of Petroleum Engineers. URL: https://doi.org/10.2118/71342-ms, doi:10.2118/71342-ms.

Peacock, D., Harris, S., Mauldon, M., 2003. Use of curved scanlines and boreholes to predict fracture frequencies. Journal of Structural Geology 25, 109-119. URL: https://doi.org/10.1016/s0191-8141(02)00016-0, doi:10.1016/s0191-8141(02)00016-0.

Pedersen, S.I., Randen, T., Sonneland, L., Steen, Ø., 2002. Automatic fault extraction using artificial ants, in: SEG Technical Program Expanded Abstracts 2002, Society of Exploration Geophysicists. URL: https://doi.org/10.1190/1.1817297, doi:10.1190/1.1817297.

Rank-Friend, M., Elders, C.F., 2004. The evolution and growth of central graben salt structures, salt dome province, danish north sea. Geological Society, London, Memoirs 29, 149164. URL: https://doi.org/10.1144/gsl.mem.2004.029.01.15, doi:10.1144/gsl.mem.2004.029.01.15.

Rasmussen, E.S., Vejbæk, O.V., Bidstrup, T., Piasecki, S., Dybkjær, K., 2005. Late cenozoic depositional history of the danish north sea basin: implications for the petroleum systems in the kraka, halfdan, siri and nini fields. Geological Society, London, Petroleum Geology Conference series 6, 1347-1358. URL: https://doi.org/10.1144/0061347, doi:10.1144/0061347.

Schlumberger, 2006. Fault resolution improved for norsk hydros varg field. case study: Variance cube software enhances imaging and reduces processing time. URL: http://www.slb.com///media/Files/software/case_studies/varcube_cs.ashx. accessed November 20th 2017.

Terzaghi, R.D., 1965. Sources of error in joint surveys. Géotechnique 15, 287-304. URL: https://doi.org/10.1680/geot.1965.15.3.287, doi:10.1680/geot.1965.15.3.287. 
Westaway, R., 1994. Quantitative analysis of populations of small faults. Journal of Structural Geology 16, 1259-1273. URL: https://doi.org/10.1016/0191-8141(94)90068-x, doi:10.1016/01918141(94)90068-x. 